\title{
Study on Etiquette Education of Rural Left-behind Students
}

\author{
Wang $\mathrm{Li}^{1}$, Yang Bin ${ }^{1,2}$ \\ ${ }^{1}$ China West Normal University, Nanchong, Sichuan, 637009 \\ ${ }^{2}$ Southwest Jiaotong University, Chengdu, Sichuan, 611756
}

Keywords: left-behind students, moral behavior, etiquette education

\begin{abstract}
With the continuous development of China's economic reform, a large number of surplus rural labor forces have left the land and their loved ones to work in urban areas. While contributing to the economic development of China, this group has also created a special new education group of left-behind students. This special group of "different" people is the result of family education, social care and school management. As a result, their negligence has exerted negative effects on developing civilized etiquette. Schools, families and the community need a correct and comprehensive understanding of this group and promote the development of their civilized and ceremonial behavior habit.
\end{abstract}

\section{Introduction}

With the reform and opening up and the globalization of the economy, people's lives are also changing quietly. However, the development of civilized etiquette of different area is unbalanced. Most of the left-behind students are from remote rural families. Their economic conditions are poor [1]. The paper first analyzes the status among left-behind students in rural areas, and then discuss the reasons behind the lack of etiquette education for left-behind students in rural areas. In the end, there are some suggestions on improving the rural students left etiquette education.

\section{The Analysis of the Status of Civilized Etiquette among Left-behind Students in Rural Areas}

\subsection{Staying students poor personal hygiene}

Most of the left-behind students are from remote rural families. Their economic conditions are poor. Their parents are generally poorly educated, their thinking is backward and their moral cultivation is unsatisfactory. Many parents neglect children's ideological, moral, ethical and behavioral education. Moreover, many of the left-behind students are taken care of by grandparents, and some even take care of themselves. Grandparents, because of their high age, taking care of themselves is still difficult, the care of grandchildren often seems powerless. Therefore, they are often very casual in their life [1]. Especially during the holidays, they are busy with delays in farm work or the other. Some of them can not eat on time. Some eat only two meals a day. As for leaving students to shampoo, wash clothes and take a shower Life often appears to be extremely luxurious, guardian simply unable to develop personal hygiene habits of left-behind students. Although the school usually spends a lot of time cultivating students' health habits, due to the family environment of the special group of left-behind children, family supervision and family conditions have led to their lazy behavior and the current situation of poor health habits.

\subsection{Poor behavior habits of left-behind students}

First of all, the uncivilized behavior of left-behind students in the classroom are: many left-behind students in the classroom did not sit and phase, and some even put their feet on the stool half-sit squatting; sometimes the teacher said on the podium, students in the following, even graffiti and doodling, do not listen to the teacher lectures; even teachers into the classroom when the students stood up, some left-behind students standing with some students bent over, and some 
students simply sitting, still eating in the classroom[2]. What is more, in the classroom with the teacher directly to the mouth, insulted beat the teacher. Second, the uncivilized behavior of left-behind students during and after class are as follows: many left-behind students often smoke, drink alcohol, fight and abuse others after class; swear and sob; they do not shout reports in or out of their teachers' offices; or ask questions, there is no honorific; abusive, intimidating teachers; athletes throw litter everywhere, to other classes of students drank nostalgia; to wear slippers, shorts, vests to schools and classrooms; campus or outside the school teachers do not say hello to the teacher; spitting and littering in classrooms and campus areas. Thirdly, the uncivilized ritual behaviors of school students at home and in the community mainly include littering in communities and streets, destruction of public facilities, disregard of decency and abusive behavior in the streets, merchandise does not give money; and some idle members of the community mix, or even steal things, fight, stir up trouble.

\subsection{Left behind students interpersonal indifference}

Left behind students are usually concerned about, take care not enough, so the lack of initiative to care about others, concerned about the collective motives and actions. Their apparent lack of confidence in their interactions with people can not be trusted with each other, so their relationships are indifferent. Most of them are self-centered and never take others as their hearts and do not respect them at home [1]. Parents and elders even abusive parents and parents, do not say hello to the guests at home, turned a blind eye, or even lie to deceive parents and often. Still others are left behind by relatives or by friends. For other children's children, this part of the guardian usually adopt a policy of accommodation, which is not too strict; if nothing can be done, it will be totally ignored. As long as the child is safe, you can not make big mistakes. In this special educational environment, left-behind students are prone to ideological deviation, and develop a series of unfavorable relationships such as indifference, selfishness and so on.

\section{The Reasons Behind the Lack of Etiquette Education for Left-behind Students in Rural Areas}

\subsection{Government functions not fully implemented}

In recent years, due to the gradual emergence of the education problems, psychological problems and safety problems of the left-behind students, the Central Party Committee and the State Council have also stepped up their education on the left-behind students in rural areas. The Ministry of Education has also held many discussions on the issue of "left-behind children in rural China "Special session, extensively heard the opinions of various experts, hoping to do a good job of educating left-behind children [2]. However, in the process of practical work arrangements, the organizational departments at all levels of government still find no fit point. Although many suggestions are made for the education of left-behind students and arrangements and arrangements are made, such as the quality of development at the national level Education and balanced education. However, due to restrictions on government funds and human resources, numerous work arrangements have only stopped at checking this surface. However, how the actual operation process has not followed the observation in depth, and although many problems have been identified, the government Sometimes all functional departments open their eyes to the task of completing one's task. If there is any problem, the etiquette education of the left-behind students only stays on the surface. For example, the government often organizes activities to care for left-behind students, Stay in the propaganda, photography, television coverage level, and the latter part of the implementation and quality control of the process has not followed up.

\subsection{The negative impact of social environment on the left-behind students}

With the advent of the information age, the spread of media such as the Internet, film, television and the like has accelerated the rate of various cultural thoughts and spiritual products, including many negative things, which brought about a great deal of education for the left-behind students big 
impact and impact [2]. Now most television stations and newspapers are trying to attract the attention of their audiences and wantonly advocate the idea of supremacy of money. Homicides, brutal and cruel images can be seen everywhere. This has far-reaching consequences for left-behind students who are not well-resolved and mentally immature, and their social values and outlook on life have had a great impact on them, making them only recognize money, do not usually care about others, self-centered, money-centered. Especially in the media rendering, many left-behind students blindly chasing stars, as long as his favorite star, regardless of each other's good or bad aspects have no choice to imitate, because of their limited experience, curiosity and curiosity , accept new things fast, a lot of things will develop from appreciation to recognition, from unintentional imitation to conscious pursuit, all of which make their behavior and moral norms have been adversely affected, or even some low-level vulgar behavior as the visual for unconventional, fully accepted.

\subsection{Exam-oriented education leads to the absence of etiquette education in schools}

Although in recent years the country has also proposed to develop quality education, we must pay attention to the cultivation of students' overall quality. However, from the current situation, our country's basic education still has a profound imprint of exam-oriented education. In the current education system, students are subject to parents, teachers and principals, and teachers and principals are subject to education administration. Students want to achieve their goals admitted to the ideal university, you have to go through numerous exams, and countless tests, which makes students only one mind to learn, the school only one thought of teaching. Under these multiple pressures, schools and teachers will devote all their energy and time, as well as the emphasis on education, to teaching achievements and improving enrollment. This naturally neglects children's training and education in other comprehensive qualities, which to a certain extent leads to the lack of school education on student civilization and etiquette. Many schools do not put specific arrangements for etiquette education into schools normative courses, making etiquette education is not possible.

\subsection{Family etiquette educational work laissez-faire}

Most children are now only children, so families are mostly spoiled for their children's education. What children want to do what you want what you want, usually at home children do not require children to do anything, for children made excessive demands do not stop the child's indulgence or improper behavior is not harsh criticism, only know blindly care, do not pay any attention to educating children's personality, psychology, values and moral values, which makes the child can not correctly distinguish between right and wrong for their behavior, easy to form a selfish, do not understand politeness, bad unity, shirk its responsibility, do not know love and gratitude, do not care about the collective, they always think that parents and teachers are their dedication to all. This allows children to develop self-centered thinking that is not as good as the tradition of "caring for others and respecting others."

\section{Improve the Rural Students Left Etiquette Education Path Analysis}

\subsection{To form a universal atmosphere of civilized etiquette knowledge}

The necessary civilized etiquette knowledge is the basis for people to form a good civilized etiquette and behavior. And a person's good civilized etiquette and intellectual behavior is not born, but acquired through acquired education and training. As far as the current situation of students and parents is concerned, their etiquette knowledge is generally weaker. To change this situation, various means must be adopted to promote and popularize the knowledge of civilized etiquette on the whole social level, Students "know the truth, but also know why they are", and in the knowledge of the situation to do to further promote the development of student civilization and etiquette education [3]. The implementation of etiquette education in all aspects of society, allowing students to participate in and practice and experience in person, so that etiquette education in social practice gradually transformed into their own qualities, internalized for their own quality, thereby enhancing 
students' cultural etiquette. And let the public in civilized etiquette education in schools, communities and at home to carry out a variety of etiquette activities to promote etiquette knowledge. And through the "supervision group" to urge students, parents, community civilized etiquette behavior, so as to promote the formation of universal ritual behavior.

\subsection{Set up a special civilized etiquette education curriculum}

When setting up a school curriculum, schools should set up special etiquette education courses. However, many schools did not do this. They basically set up examination-oriented courses, and etiquette education courses should become normal courses in the students' curriculum. New students entering new school for a lot of things do not understand, it is easy to primary school stage many bad thoughts and bad behavior continue to secondary school learning and life, so the behavior of the first time to develop is very important [3]. Therefore, the first day can be opened a week etiquette class, the second and third days according to the actual situation of students and courses to open a ceremonial lesson every other week. The contents of the opening may be formulated in accordance with the Guidance Outline for Education of Civilized and Manners Primary and Secondary Schools, the Code for Middle School Students and the Code of Practice for Secondary School Students.

\subsection{Improve the ritual accomplishment of parents and teachers}

In the process of student development, the most influential people who are contacted with students are teachers and parents. Therefore, parents and teachers should set examples for them. The family is the child's first school, and parents are the children's first teachers. Family education plays a crucial role in children's etiquette education. The level of student etiquette to a large extent, the cultural background of the student family, parents should make it clear the purpose of etiquette education requires parents to raise awareness and improve their own etiquette and accomplishment, to set a good example for children so that children get along with their parents. The process will be subtly affected, which is conducive to improving the quality of students' own etiquette. Teachers should start from me and constantly improve their own etiquette and literacy in daily teaching activities and daily life to pay attention to their demeanor, polite treatment of students, continuous etiquette education penetration, with a good instrument style is students as role models.

\subsection{Establish a school, family and community "Trinity" integrated management mechanism}

The primary responsibility of the trinity integrated management body is to make decisions and coordinate management on the ideological and moral education of left-behind students, the content of polite education, the conduct of activities, and the establishment of habits and habits. The personnel of the tripartite agencies work together to manage and educate people from different aspects [2]. The leader group is chaired by the president and holds regular member meetings to listen to the new problems and achievements in polite education management, analyze the causes together, and summarize the common understanding of experience. Formulate the general goal of etiquette education, and put forward the goal of etiquette education in phases so that students can give full play to their role in education and gradually form good etiquette habits. The community "Inspectorate" widely publicized the school's education measures and the ritual behaviors that citizens should insist on, so as to enable the masses to participate in this contingent and pay close attention to the healthy growth of minors. Through the "guide group", the Family Committee can make parents aware of their own ritual habits and affect their children. According to the phased education goal of the school, the Committee proposes the etiquette and behavior requirements of the children at home, keeps pace with the schools, and manages and educates the children Guide children to persevere, eventually forming a good habit of etiquette.

\section{Conclusions}

All in all, in order to improve the etiquette education of rural left-behind students, we have to analyse the status among left-behind students in rural areas, and then figure out the reasons behind 
the lack of etiquette education for them. There are several methods that we can do to better the education, such as forming a universal atmosphere of civilized etiquette knowledge, offering special civilized etiquette education curriculum, improving the ritual accomplishment of parents and teachers.

\section{Acknowledgements}

This article is the result of the project "Diversity and Collaboration: Educational Service Improvement Mechanism in Yi Nationality Areas in Sichuan Province" (Project Number: 416515) at China West Normal University

\section{References}

[1] Ma Hengmin. On broaden the content of moral education thinking [J]. Heilongjiang Higher Education Research, 2006, (4), 45-46.

[2] Yang Min, Zhong Lanping. How to carry out moral education in high school in the new period [J]. Heihe Education, 2011, (9), 78-79.

[3] Shi Yunqing, Hu Xiuli. Discussion on Moral Education in Rural Middle Schools under the New Situation [J]. Education and Research, 2010, (5), 68-70. 